\title{
Daily almond consumption in cardiovascular disease prevention via LDL-C change in the U.S. population: a cost- effectiveness analysis
}

\author{
Jifan Wang ${ }^{1 *}$, Michelle A. Lee Bravatti ${ }^{1}$, Elizabeth J. Johnson ${ }^{1}$ and Gowri Raman²
}

\begin{abstract}
Background: Heart disease is the leading cause of death in the United States. The U.S. Food and Drug Administration approved the health claim that $1.5 \mathrm{oz}(42.5 \mathrm{~g})$ of nut intake may reduce the risk of cardiovascular disease. Previous studies have focused on the cost-effectiveness of other foods or dietary factors on primary cardiovascular disease prevention, yet not in almond consumption. This study aimed to examine the costeffectiveness of almond consumption in cardiovascular disease primary prevention.

Perspective \& Setting: This study assessed the cost-effectiveness of consuming $42.5 \mathrm{~g}$ of almond from the U.S. healthcare sector perspective.

Methods: A decision model was developed for $42.5 \mathrm{~g}$ of almond per day versus no almond consumption and cardiovascular disease in the U.S. population. Parameters in the model were derived from the literature, which included the probabilities of increasing low-density lipoprotein cholesterol, developing acute myocardial infarction and stroke, treating acute myocardial infarction, dying from the disease and surgery, as well as the costs of the disease and procedures in the U.S. population, and the quality-adjusted life years. The cost of almonds was based on the current price in the U.S. market. Sensitivity analyses were conducted for different levels of willingness-to-pay, the probabilistic sensitivity analysis, ten-year risk prevention, different costs of procedures and almond prices, and patients with or without cardiovascular disease.

Results: The almond strategy had $\$ 363$ lower cost and 0.02 higher quality-adjusted life years gain compared to the non-almond strategy in the base-case model. The annual net monetary benefit of almond consumption was \$1421 higher per person than no almond consumption, when the willingness to pay threshold was set at $\$ 50,000$ for annual health care expenditure. Almond was more cost-effective than non-almond in cardiovascular disease prevention in all the sensitivity analyses.
\end{abstract}

Conclusion: Consuming $42.5 \mathrm{~g}$ of almonds per day is a cost-effective approach to prevent cardiovascular disease in the short term and potentially in the long term.

Keywords: Almond, Cost-effectiveness analysis, Cardiovascular disease, Heart disease, Stroke, Myocardial infarction

\footnotetext{
* Correspondence: Jifan.wang@tufts.edu

${ }^{1}$ Tufts University Friedman School of Nutrition and Policy, 150 Harrison Ave, Boston, MA 02111, USA

Full list of author information is available at the end of the article
}

(C) The Author(s). 2020 Open Access This article is licensed under a Creative Commons Attribution 4.0 International License, which permits use, sharing, adaptation, distribution and reproduction in any medium or format, as long as you give appropriate credit to the original author(s) and the source, provide a link to the Creative Commons licence, and indicate if changes were made. The images or other third party material in this article are included in the article's Creative Commons licence, unless indicated otherwise in a credit line to the material. If material is not included in the article's Creative Commons licence and your intended use is not permitted by statutory regulation or exceeds the permitted use, you will need to obtain permission directly from the copyright holder. To view a copy of this licence, visit http://creativecommons.org/licenses/by/4.0/ The Creative Commons Public Domain Dedication waiver (http://creativecommons.org/publicdomain/zero/1.0/) applies to the data made available in this article, unless otherwise stated in a credit line to the data. 


\section{Background}

Almonds contain a variety of bioactive components that have been individually related to cardiovascular health [1]. Almonds, along with other tree nuts, are good sources of mono- and polyunsaturated fats that have been shown to lower blood lipid levels. Although there is no direct study investigating the effect of almond on cardiovascular disease outcomes, our recent metaanalysis found that almond consumption reduced the level of cardiovascular disease (CVD) risk factors, such as low-density lipoprotein cholesterol (LDL-C), total cholesterol, body weight, and apolipoprotein B [2]. The qualified health claim for tree nuts and heart health by the U.S. Food and Drug Administration states, "Scientific evidence suggests but does not prove that eating 1.5 ounces per day of most nuts, as part of a diet low in saturated fat and cholesterol, may reduce the risk of heart disease" [3].

Cardiovascular disease treatments are usually expensive, which include medications and invasive or noninvasive surgeries. Between 2014 and 2015, the estimated direct cost of CVD and stroke was $\$ 213.8$ billion in the U.S [4]. Although some studies have been conducted to assess the cost-effectiveness of those treatments, [5] findings suggest that treatments such as statin medication are effective, but can have side-effects on health [6].

In contrast, tree nuts as part of a healthy diet, typically do not have any side effects on consumers, with the exception of tree nut allergies [7]. Given the fact that nuts, including almonds, are relatively expensive, it is not clear whether consuming almonds on a daily basis would be a cost-effective way to prevent CVD. The purpose of this research is to determine whether the consumption of almonds is an economically preferred alternative for CVD primary prevention using both short-term base case analysis and 10-year risk prevention.

\section{Methods}

\section{Target population and study perspective}

The target population of this study is U.S. adults with increased risk of type 2 diabetes, including overweight or obese, or normal-weight adults with a strong family history of diabetes, based on the original intervention study we used for the analysis. The mean age of participants in the original study was approximately 30 years in both almond and non-almond group with an average body mass index (BMI) of no less than $27 \mathrm{~kg} / \mathrm{m}^{2}$. The randomized control trial recruited 150 participants, of which 48 men and 89 women completed all study activities. Each of the five arms in the study had similar sex ratios [8]. This current study applied the healthcare sector's perspective to inform individual decisions on using daily almond consumption for CVD primary prevention.

\section{Base-case decision model}

We developed a decision model for CVD primary prevention among adults with $42.5 \mathrm{~g}$ of $(1.5 \mathrm{oz})$ almond consumption per day (almond strategy), as compared with no almond consumption (non-almond strategy) to project 1-year health outcomes and CVD-related costs (Fig. 1). Previous studies on statin have shown that 1 year could be sufficient for CVD primary prevention [9]; therefore, we chose to use 1 year for our base-case analysis and to further assess the long-term effect in the sensitivity analysis. We referred to a previous paper to develop the model structure [10]. Our previous metaanalysis found a significant decrease in LDL-C among almond intervention groups, as compared with no almond controls [2]. Level of LDL-C was applied as the determinant for possible risk for future CVD events. Individuals with lower or normal levels of LDL-C, who did not have CVD, started in the "disease-free" health state, either in the almond or non-almond strategy. We assumed that all the probabilities of CVD events were the same in the almond and non-almond strategy if their LDL-C increased. The probabilities of changes in LDL-C for the almond and non-almond strategy were obtained through contact with the study authors [8]. Transitions from the "disease-onset" health state to CVD events, including acute myocardial infarction (MI), stroke, and subsequent procedures or outcomes were based on probabilities derived from targeted literature reviews (Table 1). The probabilities of developing outcomes in the one-year time frame were converted from the original data to rates and then to probabilities according to the following equations, [28] assuming that the risk was the same every year:

$$
\begin{aligned}
& r=\frac{-\ln (1-p)}{t} \\
& \text { Probability }=1-\text { exp }^{-r t^{\prime}}
\end{aligned}
$$

where $r$ is the rate from original data; $p$ is the original probability for the time frame in the literature; $t$ is the original study duration; $t^{\prime}$ is the time frame in the analysis, equaling one in our base-case model and ten in the 10-year risk prevention model.

After an acute MI event, health states were further classified as: 1 ) undergoing a procedure (coronary artery bypass graft (CABG), percutaneous transluminal coronary angioplasty (PTCA)), 2) no procedure (but managed medically), 3) having a MI-related death. After an event of stroke, health states were further classified as: 1) asymptomatic stroke, 2) recurrent stroke, and 3) death from stroke. Once in a CVD disease state, individuals could not transition back to a "disease-free" state. After an acute disease state, individuals transitioned to a chronic heart disease (CHD) state. 


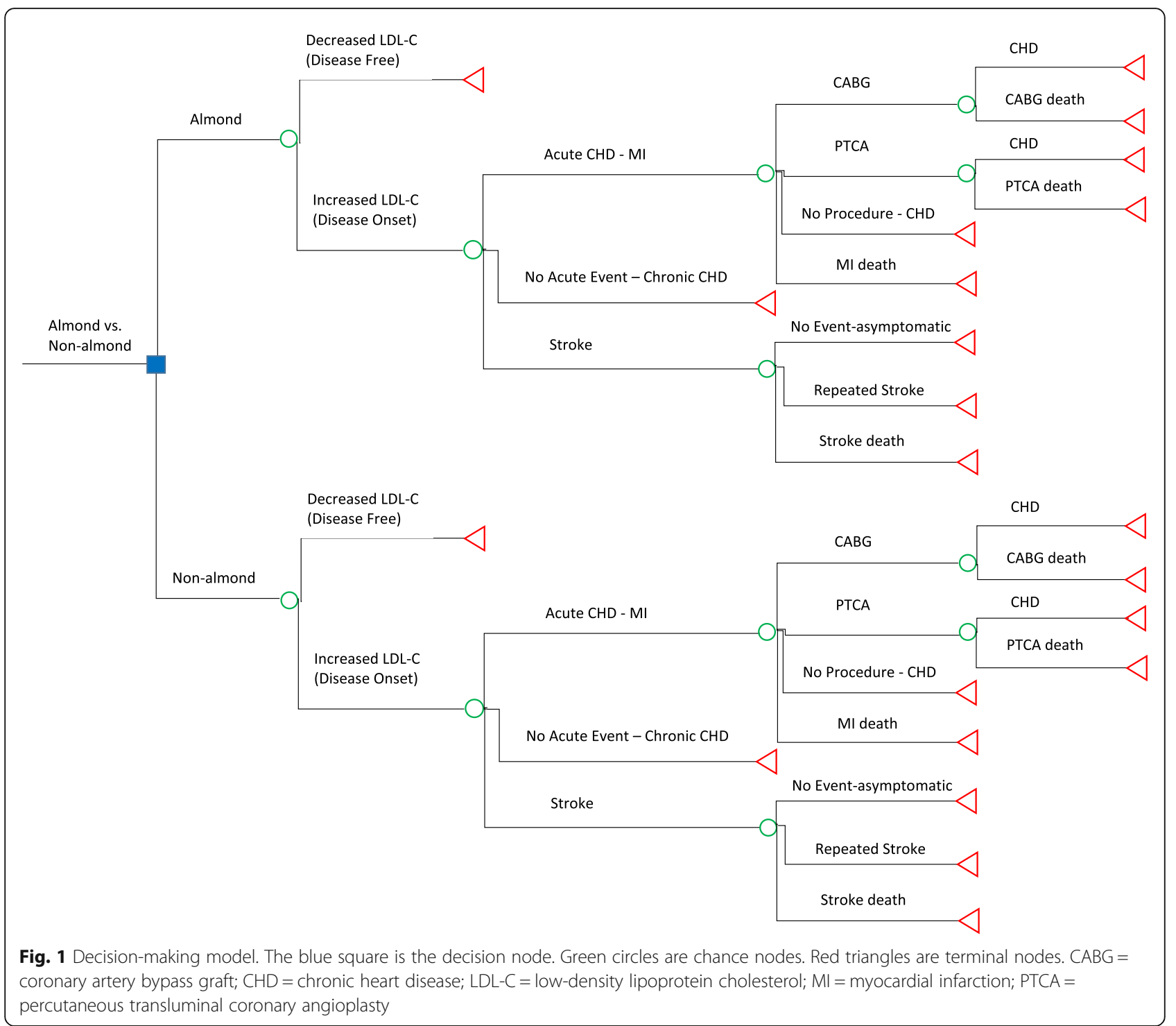

\section{Cost of therapy}

The cost of almonds was derived from a publicly available source as the current price of almonds in the U.S. market [19]. The annual cost was calculated based on the consumption of $42.5 \mathrm{~g}$ per day. The costs of CVD events and costs of treatments were derived from recent literature [21-24]. The costs of each procedure (i.e., CABG or PTCA) included procedural and physician fees as well as costs for hospital stays and ancillary services. For procedures following the CHD state, we considered costs for re-hospitalization, outpatient and rehabilitation services, medication, and physician fees [22]. The costs for medical therapy and emergency admission for MI were used for the "no procedure" outcome. For the costs for direct death due to MI, we included physician fees, hospital stay expenses and ancillary services [21]. We used the first-year follow-up costs for stroke medication and rehabilitation as the cost for recurrent stroke [23]. The five-day hospitalization cost for cerebrovascular disease was used as the cost for death from stroke since the average cost and the length of stay is similar between the two events [24]. All the costs were adjusted to 2012 U.S. dollars, the year when the almond randomized controlled trial (RCT) [8] was conducted. Medical expenditure was adjusted using the Personal Health Care Index [29] and the almond cost was adjusted using Consumer Price Index [30].

\section{Quality-adjusted life year}

Quality-adjusted life year (QALY) for each outcome was used as the effectiveness in the model. We assumed that the QALY of the disease-free stage was equal to 1 . All input parameters in the model are listed in Table 1. 
Table 1 Input Parameters in the Decision-making Model and Source

\begin{tabular}{|c|c|c|c|}
\hline Parameter & Value & Distribution & Source \\
\hline \multicolumn{4}{|l|}{ Probability } \\
\hline \multirow[t]{3}{*}{ Increase in LDL-C } & 29\% (almond) & - & Tan et al. [8] $]^{\mathrm{a}}$ \\
\hline & $41 \% \pm 12 \%$ (almond) & Beta & Tan et al.[8] ${ }^{a}$ \\
\hline & $44 \%$ (non-almond) & - & Tan et al.[8] $]^{a}$ \\
\hline \multirow[t]{2}{*}{ For CVD patients } & 25\% (almond) & - & Chen et al. [11] \\
\hline & 35\% (non-almond) & - & Chen et al. [11] \\
\hline \multirow[t]{3}{*}{ Developing MI } & $0.38 \%$ & - & Pikula et al. [12] \\
\hline & $3.75 \% *$ & - & Pikula et al. [12] \\
\hline & $1.04 \% \pm 0.91 \%$ & Beta & Multiple sources $[12,13]$ \\
\hline Death due to Ml & $14 \%$ & - & Benjamin et al. [14] \\
\hline Taking CABG & $0.11 \%$ & - & Epstein et al. [15] \\
\hline Death due to $C A B G$ & $1.85 \%$ & - & Eisenberg et al. [16] \\
\hline Taking PTCA & $0.37 \%$ & - & Epstein et al. [15] \\
\hline Death due to PTCA & $1.82 \%$ & - & Benjamin et al. [14] \\
\hline \multirow[t]{3}{*}{ Developing stroke } & $0.25 \%$ & - & Pikula et al. [12] \\
\hline & $2.46 \% *$ & - & Pikula et al. [12] \\
\hline & $0.099 \% \pm 0.11 \%$ & Beta & Multiple sources $[12,17,18]$ \\
\hline Recurrent stroke & $30.33 \%$ & - & Benjamin et al. [14] \\
\hline Death due to stroke & $21.82 \%$ & - & Benjamin et al. [14] \\
\hline \multicolumn{4}{|l|}{ Cost (in 2012 USD) } \\
\hline \multirow[t]{2}{*}{ Almond } & $\$ 156^{\mathrm{b}}$ & - & Trader Joe's [19] \\
\hline & $\$ 1369^{*}$ & - & Trader Joe's [19] \\
\hline Organic almond & $\$ 470$ & - & US market price [20] \\
\hline CABG Procedure & $\$ 37,448$ & - & Cohen et al. [21] \\
\hline Sensitivity & $\$ 29,609$ & - & Caruba et al. [22] \\
\hline \multirow[t]{2}{*}{ Follow-up of CABG } & $\$ 6918$ & - & Cohen et al. [21] \\
\hline & $\$ 60,548^{*}$ & - & Cohen et al. [21] \\
\hline Failure to Rescue after CABG & $\$ 5733^{c}$ & - & Cohen et al. [21] \\
\hline PCI Procedure & $\$ 31,036$ & - & Cohen et al. [21] \\
\hline Sensitivity & $\$ 13,688$ & - & Caruba et al. [22] \\
\hline \multirow[t]{2}{*}{ Follow-up of $\mathrm{PCl}$} & $\$ 9489$ & - & Cohen et al. [21] \\
\hline & $\$ 83,050^{*}$ & - & Cohen et al. [21] \\
\hline Failure to Rescue after $\mathrm{PCl}$ & $\$ 9243^{c}$ & - & Cohen et al. [21] \\
\hline Treatment to Acute Ml & $\$ 14,697$ & - & Cohen et al. [21] \\
\hline \multirow[t]{2}{*}{ Treatment to Chronic Heart Disease } & $\$ 3365$ & - & Caruba et al. [22] \\
\hline & $\$ 45,709^{*}$ & - & Caruba et al. [22] \\
\hline \multirow[t]{2}{*}{ Recurrent Stroke } & $\$ 61,988$ & - & Engel-Nitz et al. [23] \\
\hline & $\$ 330,528^{*}$ & - & Engel-Nitz et al. [23] \\
\hline Death due to Stroke & $\$ 11,377$ & - & Russo \& Andrews [24] \\
\hline \multicolumn{4}{|l|}{ Utilities } \\
\hline \multirow[t]{2}{*}{ Disease free } & 1 QALY & - & - \\
\hline & 8.75 QALYS $^{*}$ & - & - \\
\hline \multirow[t]{2}{*}{ Successful CABG } & 0.82 QALY & - & Elizabeth et al. [25] \\
\hline & 7.14 QALYS $^{*}$ & - & Elizabeth et al. [25] \\
\hline
\end{tabular}


Table 1 Input Parameters in the Decision-making Model and Source (Continued)

\begin{tabular}{llll}
\hline Parameter & Value & Distribution & Source \\
\hline Successful PCl & 0.85 QALY & - & Elizabeth et al. [25] \\
Chronic Heart Disease & 7.44 QALYS & - & Elizabeth et al. [25] \\
& 0.86 QALY & - & Bakhai et al. [26] \\
Recurrent Stroke & 7.53 QALYS & Bakhai et al. [26] \\
& 0.48 QALY & - & Nelson et al. [27] \\
Death & 4.20 QALYS & - & Nelson et al. [27] \\
\hline
\end{tabular}

Abbreviations: $\mathrm{CABG}=$ coronary artery bypass graft; $\mathrm{LDL}-\mathrm{C}=$ low-density lipoprotein cholesterol; $\mathrm{MI}=$ myocardial infarction; $\mathrm{PCl}=$ percutaneous coronary intervention; PTCA = percutaneous transluminal coronary angioplasty. Note that PTCA and PCI were used interchangeably in data collection. ${ }^{\mathrm{a}}$ Data is obtained from the request to author. ${ }^{b}$ Cost of almond was calculated based on the price of $\$ 4.99 / \mathrm{lb}$. and consuming $42.5 \mathrm{~g}$ almond every day. ${ }^{\mathrm{c}} \mathrm{Failure}$ to rescue after procedures includes the cost of re-hospitalizations, physician fees, outpatient services, and medication cost. ${ }^{*}$ Highlighted data was used in the 10 -year model

\section{Cost per quality-adjusted life year threshold}

We used multiple cost-effectiveness thresholds based on resources available for the typical U.S. decision maker [31]. The threshold of \$50,000-per-QALY was used as the lower boundary, which has been the ratio established by the U.S. government in 1970s that mandates Medicare coverage for end-stage renal disease (ESRD) patients [32]. The threshold of $\$ 100,000-$ per-QALY was used as the willingness to pay (WTP) of twice the per capital annual income of $\$ 54,000$, which has been suggested by economists and the World Health Organization (WHO) as a reasonable threshold based on empirical estimates and economic theory [32]. The highest threshold of \$200,000-perQALY was based on the increase in health spending over time and surveys asking people about their WTP in exchange of health gains [33, 34].

\section{Sensitivity analyses}

We performed several one-way sensitivity analyses, in which the cost-effectiveness ratio was calculated by altering the following parameters identified from targeted literature reviews: 1 ) the probabilities of developing CVD in 10 years; 2) the costs of CABG and PTCA procedures; 3 ) the cost of almonds; and 4) the LDL-C response among participants with existing CVD. In the 10 -year model, we applied a $3 \%$ per year discount rate to costs and effectiveness $[35,36]$.

We further conducted Monte Carlo probabilistic sensitivity analysis (PSA) with 10,000 simulations to address uncertainty. We extracted data from Pikula et al. and other literature $[13,17,18]$ to estimate the distributions of key (parameters)

Preferred alternative was chosen based on the net monetary benefit (NMB):

$$
\widehat{N M B}=\lambda \times \Delta \bar{E}-\Delta \bar{C}
$$

where $\lambda$ is the maximum WTP for health care, $\Delta \bar{E}$ is the difference in the mean effectiveness of two strategies, and $\Delta \bar{C}$ is the difference in the mean cost of two strategies [37]. TreeAge Pro 2018 was used to conduct the analyses.

\section{Results}

\section{Base-case decision model}

The base-case decision model for 1 year showed that consuming $42.5 \mathrm{~g}$ of almonds per day was a preferable strategy to prevent CVD outcomes such as MI, CHD, and stroke (Table 2). The results showed that $42.5 \mathrm{~g}$ of almond consumption every day costs an individual \$1211/QALY and no almond consumption costs \$1625/ QALY. The annual NMB was $\$ 46,794$ and $\$ 45,373$ for the almond and non-almond strategy, respectively, when the WTP was $\$ 50,000$ for individual health care expenditure every year. A negative incremental costeffectiveness ratio (ICER) was obtained due to lower costs of almond consumption in relation to the higher amount of QALYs gained; therefore, the non-almond strategy was dominated. When the WTP was increased to $\$ 100,000$ and $\$ 200,000$, the NMB of almond strategy correspondingly increased to $\$ 94,749$ and $\$ 190,658$ while the NMB of non-almond increased to $\$ 92,270$ and $\$ 186,064$; the almond strategy always had a higher NMB than the non-almond strategy regardless of the WTP.

\section{Sensitivity analyses}

In the PSA, on average, almond strategy had $\$ 34 \pm 414$ increased cost and $0.005 \pm 0.02$ increased QALY compared to non-almond strategy. The NMB for consuming almond was $\$ 45,542 \pm 1245$ while the NMB for nonalmond was $\$ 45,333 \pm 84$. The almond strategy had a 58 , 60 , and $61 \%$ probability of being cost-effective at the WTP of $\$ 50,000, \$ 100,000$, and $\$ 200,000$, respectively (Figs. 2 and 3).

When we expanded the time horizon to 10 years, the non-almond strategy was still dominated as it had a higher cost, but a lower effectiveness compared to the almond strategy (Table 2). The 
Table 2 Results of Decision Model and Sensitivity Analyses

\begin{tabular}{|c|c|c|c|c|c|c|c|}
\hline & $\begin{array}{l}\text { Cost } \\
(\$)\end{array}$ & $\begin{array}{l}\Delta C \\
(\$)\end{array}$ & Outcome (QALYS) & $\Delta \mathrm{E}(\mathrm{QALYS})$ & $\begin{array}{l}\text { C/E } \\
\text { (\$/QALY) }\end{array}$ & $\begin{array}{l}\text { ICER } \\
\text { (\$/QALY) }\end{array}$ & $\begin{array}{l}\text { NMB } \\
(\$)\end{array}$ \\
\hline \multicolumn{8}{|l|}{ Decision model } \\
\hline \multicolumn{8}{|l|}{$W T P=\$ 50,000$} \\
\hline Non-almond & 1524 & Ref & 0.94 & Ref & 1625 & \multirow[t]{2}{*}{ Dominated } & 45,373 \\
\hline Almond & 1161 & -363 & 0.96 & 0.02 & 1211 & & 46,794 \\
\hline \multicolumn{8}{|l|}{$W T P=\$ 100,000$} \\
\hline Non-almond & 1524 & Ref & 0.94 & Ref & 1625 & \multirow[t]{2}{*}{ Dominated } & 92,270 \\
\hline Almond & 1161 & -363 & 0.96 & 0.02 & 1211 & & 94,749 \\
\hline \multicolumn{8}{|l|}{$W T P=\$ 200,000$} \\
\hline Non-almond & 1524 & Ref & 0.94 & Ref & 1625 & \multirow[t]{2}{*}{ Dominated } & 186,064 \\
\hline Almond & 1161 & -363 & 0.96 & 0.02 & 1211 & & 190,658 \\
\hline \multicolumn{8}{|c|}{ Sensitivity-Probabilistic Sensitivity Analysis } \\
\hline Non-almond & $1555 \pm 59$ & Ref & $0.94 \pm 0.0005$ & Ref & $1658 \pm 63$ & & $45,333 \pm 84$ \\
\hline Almond & $1589 \pm 417$ & $34 \pm 414$ & $0.94 \pm 0.02$ & $0.005 \pm 0.02$ & $1694 \pm 474$ & $-26,798 \pm 814,514$ & $45,542 \pm 1245$ \\
\hline \multicolumn{8}{|l|}{ Sensitivity-10-year model } \\
\hline Non-almond & 20,871 & Ref & 8.13 & Ref & 2566 & \multirow[t]{2}{*}{ Dominated } & 385,788 \\
\hline Almond & 15,120 & -5750 & 8.37 & 0.24 & 1806 & & 403,377 \\
\hline \multicolumn{8}{|l|}{ Sensitivity-cost of procedure } \\
\hline Non-almond & 1524 & Ref & 0.94 & Ref & 1625 & \multirow[t]{2}{*}{ Dominated } & 45,373 \\
\hline Almond & 1161 & -363 & 0.96 & 0.02 & 1210 & & 46,794 \\
\hline \multicolumn{8}{|l|}{ Sensitivity-cost of almond } \\
\hline Non-almond & 1524 & Ref & 0.94 & Ref & 1625 & \multirow[t]{2}{*}{ Dominated } & 45,373 \\
\hline Higher cost of almond & 1474 & -50 & 0.96 & 0.02 & 1537 & & 46,480 \\
\hline \multicolumn{8}{|l|}{ Sensitivity-CVD patients } \\
\hline Non-almond & 1213 & Ref & 0.86 & Ref & 1411 & \multirow[t]{2}{*}{ Dominated } & 41,766 \\
\hline Almond & 1022 & -190 & 0.86 & 0.0001 & 1189 & & 41,962 \\
\hline
\end{tabular}

Abbreviations: C/E cost-effectiveness ratio, ICER incremental cost-effectiveness ratio, NMB net monetary benefit, $Q A L Y$ quality-adjusted life years, WTP willingness-to-pay

almond strategy cost $\$ 5750$ less, but gained 0.24 QALYs more than the non-almond strategy. The NMB for almond was $\$ 17,589$ higher than the nonalmond strategy.

In other sensitivity analyses (Table 2), the nonalmond strategy continued to be dominated even when different costs of procedures were input. The results from different procedure costs remained the same as the results from the base-case model. As the price of almond increased, it cost more money per QALY to prevent CVD by consuming almonds; however, it was still more financially viable than not consuming almonds. With the price of organic almonds, it cost \$1537/QALY for almond consumption with an NMB of $\$ 46,480$.

For secondary prevention, the almond strategy cost \$1189/QALY compared with \$1411/QALY for the nonalmond strategy, and had a higher NMB $(\$ 41,962$ for almond vs. $\$ 41,766$ for non-almond).

\section{Discussion}

This study assessed the cost-effectiveness of almond consumption in the short term and up to 10 years for CVD prevention. We found that it costs an individual $\$ 1211 /$ QALY to prevent CVD in 1 year by consuming almonds everyday versus \$1625/QALY for no almond, indicating that consuming almonds may be cost-effective to prevent CVD in the short term. It cost \$1806/QALY for almond versus \$2566/QALY for no almond in 10year CVD primary prevention; therefore, consuming almonds may be potentially cost-effective in the long term. In the sensitivity analyses, consuming almonds was also a financially viable way to prevent CVD. The nonalmond strategy was dominated in almost all sensitivity analysis except in the PSA.

Heart disease is the leading cause of death in the United States, with over 630,000 deaths in 2015 and over 140,000 stroke-related deaths in the same year [38]. The disease also lays a huge economic burden in the United 


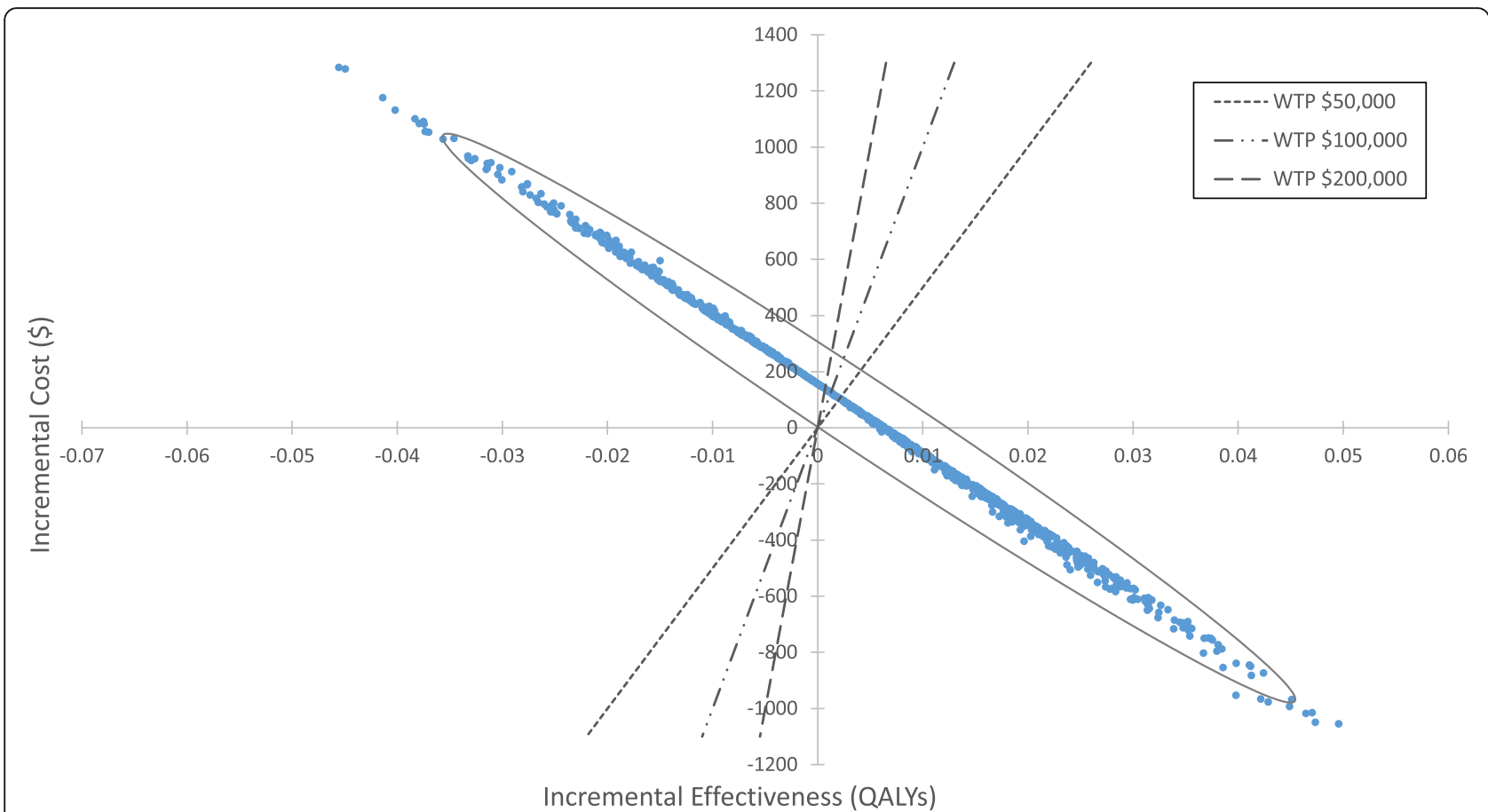

Fig. 2 Scatter plot of estimated incremental cost (\$) and incremental effectiveness (QALYS) of $1.5 \mathrm{oz}$ almond versus non-almond from the probability sensitivity analysis. Dashed lines denote the willingness-to-pay (WTP) at $\$ 50,000, \$ 100,000$, and $\$ 200,000$, respectively. The area to the right of the WTP indicates the almond strategy being cost-effective

States. Between 2014 and 2015, the estimated annual cost of CVD in the United States was $\$ 351.2$ billion. The projected total costs of CVD until 2035 will continue to increase for people in all age groups [4]. Under such disease and economic burden, cost-effective primary prevention strategies for CVD are imperative for the population.
Almonds have been studied continuously due to its cardiovascular benefits. Our recent meta-analysis showed a reduction in CVD risk factors, such as LDL-C, total cholesterol, body weight, and apolipoprotein B with almond consumption, with no difference on triglycerides, blood pressure, apolipoprotein A1, high-sensitivity C-reactive protein, and lipoprotein (a) [2]. Almonds

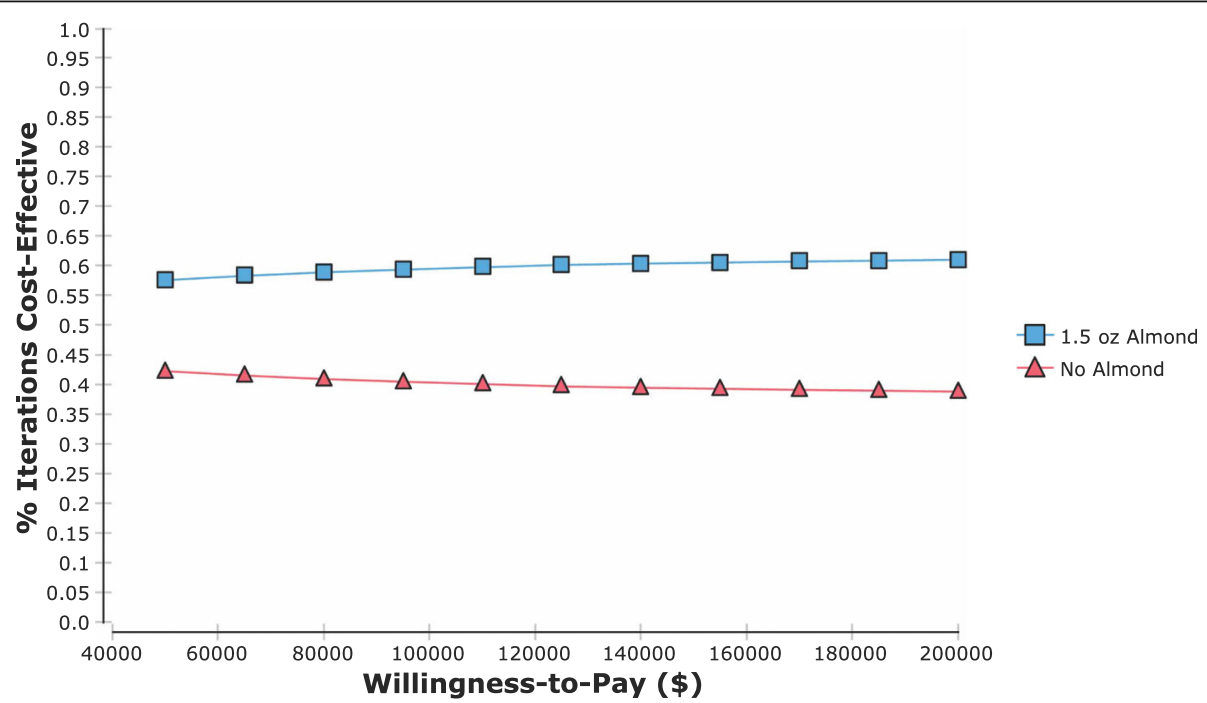

Fig. 3 Cost-effectiveness accessibility curve (CEAC) of multiple thresholds for willingness-to-pay (WTP). Red triangles depict no almond; blue squares depict $1.5 \mathrm{oz}$ almond. The WTP for health care ranged from $\$ 50,000$-per-QALY to $\$ 200,000$-per-QALY. The CEAC shows the probability of a strategy being the more cost-effective alternative under different thresholds of WTP 
contain phytochemicals such as proanthocyanidins, hydrolysable tannins, fat-soluble bioactives including vitamin $\mathrm{E}$ and phytosterols, and antioxidants that are cardio-beneficial. Other macro- and micro-nutrient components in almonds, including omega-3 fatty acids, selenium, magnesium, copper, potassium, and $\beta$ sitosterol, are also potentially cardio-protective [1].

Previous studies have focused on the cost-effectiveness of other foods or dietary factors on primary CVD prevention, [39-42] but little is known about the costeffectiveness of almonds or other tree nuts. A recent study assessed the effect of healthy food financial incentives from both societal and healthcare perspectives, showing that $30 \%$ subsidy on healthy food, including nuts, is a cost-effective way to prevent CVD and diabetes [43]. To our best knowledge, our study is the first costeffectiveness research on CVD primary prevention using an almond strategy at the individual level. In this study, we conducted a base-case model and several sensitivity analyses to assess the cost-effectiveness in the short term and the long term. The results of this study may provide some insights on individual level healthy dietary behaviors as well as population level benefits of consuming almonds.

Our study is mainly constrained by lack of available data. We derived the probabilities of developing MI and stroke from Pikula et al. in which participants had older age, higher total cholesterol levels, and 9\% diabetes, but similar sex ratio and high-density lipoprotein levels compared to our target population. Although the populations were not completely matched for all CVD risk factors, Pikula et al. was the most appropriate study that provided the probabilities for two of the key parameters for the base-case model [12]. We used LDL-C response as our mediator of CVD risk, even though the ratio of total cholesterol/high-density lipoprotein may have been a better indicator as it reflects both benefits and side effects of almonds; however, we were only able to obtain the data of LDL-C response from study authors. Due to the wide variety of health insurance options in the United States, we were not able to summarize the average premiums, deductibles, and out-of-pocket expenses for CVD treatments. Instead, we used the average healthcare cost for each treatment; consequently, our results and conclusion may only apply to the uninsured. Regarding the parameters in the PSA, we were only able to find limited data that had a different center of distribution to estimate the uncertainty of the results.

Our models had a few other limitations. For example, the focus of this study was on the U.S. population with an increased risk of type 2 diabetes using the costs of medical treatments and the probabilities of developing diseases from studies conducted in the United States. Therefore, the results may not be generalizable to populations in other countries. Furthermore, unlike medical or surgical therapies, there are no serious side effects for consuming almonds, except for tree nut allergies. Thus, our models do not take into consideration any serious side effects, which could be related to the preference of the almond strategy.

The interpretation of our results requires more caution. First, our study was based on inputs from published literature instead of primary data from an intervention cohort. Thus, the inputs were constrained by the study design of the literature, especially the probabilities. As a result, we made three assumptions in the models: 1 ) changes in LDL-C can lead to a difference in CVD risk in one year in the base-case model; 2) changes in LDL-C caused by almonds remained consistent in the ten-year sensitivity analysis; and 3) costs of almonds and procedures over time remained consistent in the ten-year sensitivity analysis. More data may be needed to estimate the costs of almonds and procedures over time.

\section{Conclusion}

Consuming almonds $42.5 \mathrm{~g}$ per day is a cost-effective approach to prevent CVD in the short term and potentially up to 10 years. Given the fact that the American population consumed an average of $2.93 \mathrm{~g}$ of almonds daily in the 2017-2018 crop year, [44] the potential benefits of increasing the almond consumption to the recommended level could be significant.

\section{Abbreviations \\ CABG: coronary artery bypass graft; CHD: chronic heart disease; CVD: cardiovascular disease; ICER: incremental cost-effectiveness ratio; LDL- C: low-density lipoprotein cholesterol; Ml: myocardial infarction; NMB: net monetary benefit; PSA: probabilistic sensitivity analysis; PTCA: percutaneous transluminal coronary angioplasty; QALY: quality-adjusted life years}

\section{Acknowledgments}

Not applicable.

\section{Authors' contributions}

G.R. and E.J.J. conceived and designed the experiments; J.W. and M.A.L.B. synthesized the data; J.W. performed the analyses; J.W., G.R., E.J.J., M.A.L.B. wrote the paper. J.W., G.R. and E.J.J. had primary responsibility for final content. All authors read and approved the final manuscript.

\section{Funding}

This study is funded by the United States Department of Agriculture and the Almond Board of California. The funder did not have a role in the model building, data collection and analysis or manuscript preparation.

\section{Availability of data and materials}

The data were publicly available in published articles or were obtained through request from Dr. Tan [8] and Dr. Chen [11]. The data used and analyzed during the current study is available from the corresponding author on reasonable request.

\section{Ethics approval and consent to participate}

The ethics approval was not necessary for this study as the data were publicly available in published articles or were obtained through request from Dr. Tan [8] and Dr. Chen [11]. No patient-level data were included. 


\section{Consent for publication}

Not applicable.

\section{Competing interests}

G.R. was a consultant for Porter Novelli and E.J.J. had additional funds from the Almond Board of California for a clinical trial at the time of the study. Other authors declare that they have no competing interests.

\section{Author details}

'Tufts University Friedman School of Nutrition and Policy, 150 Harrison Ave, Boston, MA 02111, USA. ${ }^{2}$ Tufts Clinical Evidence Synthesis Center, Tufts Medical Center, 800 Washington Street, box 63, Boston, MA 02111, USA.

Received: 25 June 2019 Accepted: 2 April 2020

Published online: 25 April 2020

\section{References}

1. Alasalvar C, Bolling BW. Review of nut phytochemicals, fat-soluble bioactives, antioxidant components and health effects. Br J Nutr. 2015; 113(Suppl 2):S68-78.

2. Lee-Bravatti MA, Wang J, Avendano EE, King L, Johnson EJ, Raman G. Almond consumption and risk factors for cardiovascular disease: a systematic review and meta-analysis of randomized controlled trials. Adv Nutr. 2019.

3. U.S. Food \& Drug Administration. Qualified Health Claims: Letter of Enforcement Discretion - Nuts and Coronary Heart Disease (Docket No 02P0505) 2003. Available from: http://wayback.archive-it.org/7993/20171114183 724/https://www.fda.gov/Food/IngredientsPackagingLabeling/ LabelingNutrition/ucm072926.htm.

4. Benjamin EJ, Muntner P, Alonso A, Bittencourt MS, Callaway CW, Carson AP, et al. Heart disease and stroke Statistics -2019 update: a report from the American Heart Association. Circulation. 2019;139(10):e56-e528.

5. Cardoso R, Blumenthal RS, Kopecky S, Lopez-Jimenez F, Martin SS. How low to go with lipid-lowering therapies in a cost-effective and prudent manner. Mayo Clin Proc. 2019;94(4):660-9.

6. Golomb BA, Evans MA. Statin adverse effects : a review of the literature and evidence for a mitochondrial mechanism. Am J Cardiovasc Drugs. 2008;8(6): 373-418.

7. Weinberger T, Sicherer S. Current perspectives on tree nut allergy: a review. Journal of asthma and allergy. 2018;11:41-51.

8. Tan SY, Mattes RD. Appetitive, dietary and health effects of almonds consumed with meals or as snacks: a randomized, controlled trial. Eur J Clin Nutr. 2013;67(11):1205-14.

9. Taylor F, Huffman MD, Macedo AF, Moore TH, Burke M, Davey Smith G, et al. Statins for the primary prevention of cardiovascular disease. Cochrane Database Syst Rev. 2013;1:Cd004816.

10. Pandya A, Sy S, Cho S, Weinstein MC, Gaziano TA. Cost-effectiveness of 10year risk thresholds for initiation of statin therapy for primary prevention of cardiovascular disease. Jama. 2015;314(2):142-50.

11. Chen CY, Holbrook M, Duess MA, Dohadwala MM, Hamburg NM, Asztalos $\mathrm{BF}$, et al. Effect of almond consumption on vascular function in patients with coronary artery disease: a randomized, controlled, cross-over trial. Nutr J. 2015;14:61.

12. Pikula A, Beiser AS, Wang J, Himali JJ, Kelly-Hayes M, Kase CS, et al. Lipid and lipoprotein measurements and the risk of ischemic vascular events: Framingham study. Neurology. 2015;84(5):472-9.

13. Kinosian B, Glick H, Garland G. Cholesterol and coronary heart disease: predicting risks by levels and ratios. Ann Intern Med. 1994;121(9):641-7.

14. Benjamin EJ, Blaha MJ, Chiuve SE, Cushman M, Das SR, Deo R, et al. Heart disease and stroke Statistics-2017 update: a report from the American Heart Association. Circulation. 2017;135(10):e146-603.

15. Epstein AJ, Polsky D, Yang F, Yang L, Groeneveld PW. Coronary revascularization trends in the United States, 2001-2008. JAMA. 2011;305(17): 1769-76.

16. Eisenberg MJ, Filion KB, Azoulay A, Brox AC, Haider S, Pilote L. Outcomes and cost of coronary artery bypass graft surgery in the United States and Canada. Arch Intern Med. 2005;165(13):1506-13.

17. Kurth T, Everett BM, Buring JE, Kase CS, Ridker PM, Gaziano JM. Lipid levels and the risk of ischemic stroke in women. Neurology. 2007;68(8):556-62.
18. Sturgeon JD, Folsom AR, Longstreth WT Jr, Shahar E, Rosamond WD, Cushman M. Risk factors for intracerebral hemorrhage in a pooled prospective study. Stroke. 2007;38(10):2718-25.

19. Trader Joe's. Raw Clifornia almonds 2018. Available from: https://www. traderjoes.com/FearlessFlyer/Article/4441\#.XFCA15VZBfc.email=0A=0ATo.

20. Nuts.com. Organic Almonds (Raw, No Shell). Available from: https://nuts. com/nuts/almonds/organic.html.

21. Cohen DJ, Lavelle TA, Van Hout B, Li H, Lei Y, Robertus K, et al. Economic outcomes of percutaneous coronary intervention with drug-eluting stents versus bypass surgery for patients with left main or three-vessel coronary artery disease: one-year results from the SYNTAX trial. Catheter Cardiovasc Interv. 2012;79(2):198-209.

22. Caruba T, Katsahian S, Schramm C, Charles Nelson A, Durieux P, Begue D, et al. Treatment for stable coronary artery disease: a network meta-analysis of cost-effectiveness studies. PLoS One. 2014;9(6):e98371.

23. Engel-Nitz NM, Sander SD, Harley C, Rey GG, Shah H. Costs and outcomes of noncardioembolic ischemic stroke in a managed care population. Vasc Health Risk Manag. 2010;6:905-13.

24. Russo CA, Andrews RM. Hospital Stays for Stroke and Other Cerebrovascular Diseases, 2005: Statistical Brief \#51. Healthcare Cost and Utilization Project (HCUP) Statistical Briefs. Rockville (MD): Agency for Healthcare Research and Quality (US); 2006

25. Magnuson EA, Farkouh ME, Fuster V, Wang K, Vilain K, Li H, et al. Costeffectiveness of percutaneous coronary intervention with drug eluting stents versus bypass surgery for patients with diabetes mellitus and multivessel coronary artery disease: results from the FREEDOM trial. Circulation. 2013;127(7):820-31.

26. Bakhai A, Stone GW, Grines CL, Murphy SA, Githiora L, Berezin RH, et al. Cost-effectiveness of coronary stenting and abciximab for patients with acute myocardial infarction: results from the CADILLAC (controlled Abciximab and device investigation to lower late angioplasty complications) trial. Circulation. 2003;108(23):2857-63.

27. Nelson RE, Saltzman GM, Skalabrin EJ, Demaerschalk BM, Majersik JJ. The cost-effectiveness of telestroke in the treatment of acute ischemic stroke. Neurology. 2011;77(17):1590-8.

28. Fleurence RL, Hollenbeak CS. Rates and probabilities in economic modelling: transformation, translation and appropriate application. PharmacoEconomics. 2007:25(1):3-6.

29. Centers for Medicare \& Medicaid Services. Table 23 National Health Expenditures; Nominal Dollars Real Dollars Price Indexes and Annua Percent Change 2018. Available from: https://www.cms.gov/ResearchStatistics-Data-and-Systems/Statistics-Trends-and-Reports/ NationalHealthExpendData/Downloads/Tables.zip.

30. Statistics BoL. CPI Inflation Calculator N.D. . Available from: https://data.bls. gov/cgi-bin/cpicalc.pl.

31. Neumann PJ, Cohen JT, Weinstein MC. Updating cost-effectiveness - the curious resilience of the $\$ 50,000-$ per-QALY threshold. N Engl J Med. 2014; 371(9):796-7.

32. Grosse SD. Assessing cost-effectiveness in healthcare: history of the $\$ 50,000$ per QALY threshold. Expert Rev Pharmacoecon Outcomes Res. 2008;8(2):165-78.

33. Hirth RA, Chernew ME, Miller E, Fendrick AM, Weissert WG. Willingness to pay for a quality-adjusted life year: in search of a standard. Med Decis Making. 2000;20(3):332-42

34. Braithwaite RS, Meltzer DO, King JTJ, Leslie D, Roberts MS. What does the value of modern medicine say about the $\$ 50,000$ per quality-adjusted lifeyear decision rule? Med Care. 2008;46(4):349-56.

35. World Health Organization. Making choices in health: WHO guide to costeffectiveness analysis. Switzerland 2003. Available from: https://www.who. int/choice/publications/p_2003_generalised_cea.pdf.

36. Ramsey S, Willke R, Briggs A, Brown R, Buxton M, Chawla A, et al. Good research practices for cost-effectiveness analysis alongside clinical trials: the ISPOR RCT-CEA. Task Force report. 2005;8(5):521-33.

37. McFarlane PA, Bayoumi AM. Acceptance and rejection: cost-effectiveness and the working nephrologist. Kidney Int. 2004;66(5):1735-41.

38. National Center for Health S. Health, United States. Health, United States, 2016: With Chartbook on Long-term Trends in Health. Hyattsville (MD): National Center for Health Statistics (US); 2017

39. Gulliford MC, Bhattarai N, Charlton J, Rudisill C. Cost-effectiveness of a universal strategy of brief dietary intervention for primary prevention in primary care: population-based cohort study and Markov model. Cost Eff Resour Alloc. 2014;12(1):4. 
40. Earnshaw SR, McDade CL, Chu Y, Fleige LE, Sievenpiper JL. Costeffectiveness of maintaining daily intake of oat beta-Glucan for coronary heart disease primary prevention. Clin Ther. 2017;39(4):804-18 e3.

41. Yang W, Gage H, Jackson D, Raats M. The effectiveness and cost-

effectiveness of plant sterol or stanol-enriched functional foods as a primary prevention strategy for people with cardiovascular disease risk in England: a modeling study. Eur J Health Econ. 2018;19(7):909-22.

42. Murray CJ, Lauer JA, Hutubessy RC, Niessen L, Tomijima N, Rodgers A, et al. Effectiveness and costs of interventions to lower systolic blood pressure and cholesterol: a global and regional analysis on reduction of cardiovasculardisease risk. Lancet. 2003;361(9359):717-25.

43. Lee Y, Mozaffarian D, Sy S, Huang Y, Liu J, Wilde PE, et al. Cost-effectiveness of financial incentives for improving diet and health through Medicare and Medicaid: a microsimulation study. PLoS Med. 2019;16(3):e1002761.

44. Economic Research Service. Fruit and Tree Nut Yearbook Tables United States Department of Agriculture: United States Department of Agriculture, 2018. Available from: https://www.ers.usda.gov/data-products/fruit-andtree-nut-data/fruit-and-tree-nut-yearbook-tables/\#Tree\%20Nuts.

\section{Publisher's Note}

Springer Nature remains neutral with regard to jurisdictional claims in published maps and institutional affiliations.

Ready to submit your research? Choose BMC and benefit from:

- fast, convenient online submission

- thorough peer review by experienced researchers in your field

- rapid publication on acceptance

- support for research data, including large and complex data types

- gold Open Access which fosters wider collaboration and increased citations

- maximum visibility for your research: over $100 \mathrm{M}$ website views per year

At BMC, research is always in progress.

Learn more biomedcentral.com/submissions 